\title{
FLOCCULATION TESTS IN HYDATID DISEASE
}

\author{
BY \\ A. FISCHMAN \\ From the Central Laboratory, Auckland Hospital, Auckland, New Zealand
}

(RECEIVED FOR PUBLICATION JULY 20, 1959)

\begin{abstract}
A new serological technique of diagnosing human hydatid disease, employing polystyrene latex particles coated with hydatid cyst fluid, and a modified technique using bentonite particles are described.

Comparison of the latex test with the complement-fixation test performed on 102 sera has shown a total agreement of $98 \%$ and an agreement of $93.1 \%$ in the positive specimens. The bentonite test and the complement-fixation test performed on 126 sera have shown a total agreement of $97.6 \%$ and an agreement of $90.1 \%$ in the positive specimens.

Both flocculation tests are simpler to perform than the complement-fixation test. They are specific, and sensitivity closely parallels that of the complement-fixation test, with $6.9 \%$ and $6.1 \%$ of the positive specimens showing higher sensitivity in the latex and bentonite tests respectively. The bentonite test was less sensitive than the complement-fixation test in one case. None of the latex tests showed less sensitivity.

The antibody active in the latex test has been demonstrated in a $\gamma$ globulin fraction of the antiserum. Some differences in the behaviour of flocculating and complement-fixing properties of sera are discussed.
\end{abstract}

The complement-fixation test has been employed routinely in the diagnosis of human hydatid disease for many decades (Dew, 1928 ; Fairley and Kellaway, 1933; Bensted and Atkinson, 1953). Other serological methods simpler than complement fixation have been reported. Thus Fairley (1923) claimed good results with a direct precipitin test. Subsequent authors found this test difficult to read and less sensitive than the complement-fixation test (Bryce, Kellaway, and Williams, 1924; Dew, 1928 ; Fairley and Kellaway, 1933). Recently an indirect haemagglutination test was described by Garabedian, Matossian, and Djanian (1957).

In the present paper two methods are described using particles, other than red cells, coated with antigen. Results are compared with the complement-fixation test. These techniques are simple, easy to read, and sensitive. The first procedure employs polystyrene latex particles, introduced by Singer and Plotz (1956) for the detection of the rheumatoid arthritis factor. The second test is an adaptation of the bentonite technique devised by Bozicevich, Tobie, Thomas, Hoyem, and Ward (1951) to diagnose trichinosis, and employed by Sadun, Norman, Allain, and King (1957) to test sera of animals inoculated with Echinococcus multilocularis. These authors suggested a possible application of the bentonite technique in human hydatid disease.

\section{Methods}

Antigen.-Fluid removed aseptically from sheep hydatid cysts is pooled and stored frozen at $-20^{\circ} \mathrm{C}$. in small aliquots. Immediately before use the fluid is thawed and centrifuged at 3,000 r.p.m. for 15 minutes. The supernatant is employed as antigen in all techniques described.

Potency is retained for at least 12 months. Suitability for both of the flocculation tests and the complement-fixation test is checked initially and at regular intervals using the same stock positive serum, also stored at $-20^{\circ} \mathrm{C}$.

Latex Hydatid Test (LHT).-The following are the materials and the method.

Stock Latex.-Polystyrene latex suspension, particle size 0.81 micron diameter (Dow Chemical Co., Midland, Michigan).

Dilute Stock Latex.-A small sample of the stock latex is diluted with distilled water until $0.1 \mathrm{ml}$. in $10 \mathrm{ml}$. of water gives $5 \%$ transmission in a "unicam" spectrophotometer. This gives the dilution factor. The dilute latex is prepared by diluting $1 \mathrm{ml}$. of the stock latex with the appropriate amount of water $(1.5 \mathrm{ml}$. water has been used in this study). This suspension keeps well at $4^{\circ} \mathrm{C}$. 
Sensitized Latex.-Dilute stock latex, $0.1 \mathrm{ml}$., is added to $10 \mathrm{ml}$. of physiological saline, mixed gently, then $0.5 \mathrm{ml}$. of antigen is added and mixed gently.

Procedure.-Sera are cleared by centrifuging if necessary. Add $0.5 \mathrm{ml}$. of fresh serum to $1.5 \mathrm{ml}$. of physiological saline in the first tube $(1: 4)$. Doubling dilutions are prepared in $1 \mathrm{ml}$. volumes, and $1 \mathrm{ml}$. sensitized latex is added to each dilution. The tubes are mixed by inversion, incubated at $37^{\circ} \mathrm{C}$. for 90 minutes, and then kept at $4^{\circ} \mathrm{C}$. overnight. Next day the tubes are centrifuged at 2,300 r.p.m. in an MSE " major" centrifuge for three minutes and read with the naked eye. A known positive serum diluted 1:8 and a saline control are tested simultaneously.

Positive tests have a wide, heavy deposit. On tapping, suspended flocs are easily visible to the naked eye. The test is considered strong when the supernatant is clear, and the resuspended flocs large; weak when the supernatant is slightly hazy and the flocs smaller. Grading flocs from 1 to $4+$ did not seem necessary. Negative tests show an opaque appearance, either without deposit, or with a small deposit easily dispersed by tapping. Occasionally tests appear doubtful, if graded on the appearance of the deposit only. They are considered negative if on resuspension no flocs are visible to the naked eye.

Bentonite Hydatid Test (BHT).-The procedures for making up the necessary solutions and the test itself are as follows:

Stock Bentonite.-This is prepared by the method of Bozicevich et al. (1951) using Volclay BC micron bentonite, American Colloid Co., Chicago, 10, Ill. The suspension may be kept at $4^{\circ} \mathrm{C}$. for at least nine months.

Stock Sensitized Bentonite.-To $10 \mathrm{ml}$. of the wellshaken stock bentonite $6 \mathrm{ml}$. antigen is added, mixed, and left overnight at $4^{\circ} \mathrm{C}$. Then $2 \mathrm{ml}$. of a $0.1 \%$ aqueous solution of methylene blue is added, the suspension thoroughly shaken, and allowed to stand for one hour at room temperature. This suspension is kept at $4^{\circ} \mathrm{C}$.

Working Sensitized Bentonite.-Ten millilitres physiological saline is added to $8 \mathrm{ml}$. of the stock sensitized bentonite, mixed and centrifuged for five minutes at 2,500 r.p.m. in an MSE "major" centrifuge. The supernatant is discarded, $15 \mathrm{ml}$. physiological saline added to the deposit, mixed and centrifuged as before. The supernatant is discarded and the deposit resuspended in $4 \mathrm{ml}$. physiological saline. Finally $0.1 \mathrm{ml}$. of a $1 \%$ solution of Tween 80 is added. The suspension is tested with a known positive, a negative serum, and a saline control. The amount of Tween 80 added may have to be increased if spontaneous flocculation occurs in the saline control. Working sensitized bentonite is kept at $4^{\circ} \mathrm{C}$. and retains its potency for at least two months.

Procedure.-Starting with a $1: 4$ dilution, serial two-fold dilutions of serum in physiological saline, using $0.1 \mathrm{ml}$. volumes, are made in 6 by $1.5 \mathrm{~cm}$. tubes. The working sensitized bentonite is shaken vigorously, and one drop is added to each dilution using a capillary pipette delivering approximately 40 drops per millilitre. After the tubes are shaken in a Kahn shaker for 10 minutes, the contents of the tubes are transferred to slides, allowed to stand for three to six minutes for full development of flocs, and examined under the low power of the microscope. A 1:8 dilution of a known positive serum and a negative control are tested simultaneously. The test is graded $4+$ if all particles are clumped into separate flocs ; $3+$ if three-quarters ; $2+$ if half ; $1+$ if onequarter and 0 if none are clumped together. Only $3+$ and $4+$ are regarded as positive tests, while $2+$ to 0 are regarded as negatives.

Complement-fixation Test.-The method used is essentially the Richardson-Wyler modification of the Wassermann technique, except that complement, haemolysin, and cells are standardized as reported before from this laboratory (Whillans, 1950). Antigen is used in two strengths, undiluted and diluted 1:2. Reagents are added in $0.25 \mathrm{ml}$. amounts. A strong positive test gives complete fixation with both strengths of antigen ; a weak positive test gives $75 \%$ fixation in one strength, and complete fixation in the other ; a doubtful test gives $75 \%$ fixation with both antigens. Less than $75 \%$ fixation is regarded as a negative reaction. All necessary controls are tested.

\section{Materials and Results}

One hundred and six sera received for the routine performance of the hydatid complementfixation test, and 20 sera received on request, were tested initially simultaneously with the bentonite hydatid test, and later with both the latex and bentonite tests. Thirty sera had a positive and one a doubtful positive complement-fixation test. In 26 of these cases hydatid disease has been confirmed surgically, but in the remaining five it was not possible to obtain information.

Comparison of Complement-fixation and Latex Hydatid Tests (102 Sera).-All sera with a positive complement-fixation test in this series (27) and the doubtful positive one had a positive latex test. All negative complement-fixation tests were accompanied by negative latex hydatid tests, with one exception. This specimen, from a case of hydatids surgically confirmed, gave a positive latex test. This gives a total agreement of $98 \%$, and $93.1 \%$ in the positive cases.

Comparison of Complement-fixation and Bentonite Hydatid Tests (126 Sera).-A positive complement-fixation test was accompanied by a positive bentonite hydatid test in all 30 sera. The serum with the doubtful complement-fixation test gave a negative bentonite hydatid test reaction. Negative complement-fixation tests were accompanied by a negative bentonite test, with two 
exceptions. These two sera, obtained from patients shortly after removal of a liver and lung hydatid cyst respectively, gave a positive bentonite hydatid test. This gives a total agreement of $97.6 \%$ and $90.9 \%$ in the positive cases (Table I).

TABLE I

COMPARISON OF POSITIVE RESULTS OF COMPLEMENTFIXATION, LATEX HYDATID, AND BENTONITE HYDATID

\begin{tabular}{|c|c|c|c|c|}
\hline \multicolumn{3}{|c|}{$\begin{array}{l}\text { Complement-fixation and Latex } \\
\text { Tests in } 29 \text { Cases }\end{array}$} & \multicolumn{2}{|c|}{$\begin{array}{c}\text { Complement-fixation and } \\
\text { Bentonite Tests in } 33 \text { Cases }\end{array}$} \\
\hline Results & & No. & Results & No. \\
\hline $\begin{array}{l}\text { Both+ }+ \\
\text { CFT } \pm \\
\text { Latex + } \\
\text { CFT- } \\
\text { Latex+ } \\
\text { Disagreement }\end{array}$ & 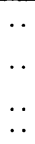 & $\begin{array}{cl}27 & (93 \cdot 1 \%) \\
1 & (3.45 \%) \\
1 & (3.45 \%) \\
2 & (6.9 \%)\end{array}$ & $\begin{array}{l}\text { Both }+ \\
\text { CFT } \pm \\
\text { Bentonite }-\ldots \\
\text { CFT- } \\
\text { Bentonite }+\ldots \\
\text { Disagreement } \ldots\end{array}$ & $\begin{array}{rr}30 & (90.9 \%) \\
1 & (3.0 \%) \\
2 & (6 \cdot 1 \%) \\
3 & (9 \cdot 1 \%)\end{array}$ \\
\hline
\end{tabular}

Comparison of Latex and Bentonite Hydatid Tests.-Positive and negative tests ran parallel, except in two cases, one test each being positive while the other flocculation test gave a negative result.

Titres.-These ranged from $1: 10$ to $1: 60$ for the complement-fixation test, from $1: 8$ to $1: 256$ for the latex hydatid test, and from $1: 4$ to $1: 128$ for the bentonite hydatid test. There was no definite correlation between titres of the three tests (Table II) or grade of positivity.

TABLE II

TITRES OF SIX SERA IN THREE HYDATID TESTS

\begin{tabular}{c|c|c}
\hline $\begin{array}{c}\text { Complement-fixation } \\
\text { Test }\end{array}$ & $\begin{array}{c}\text { Latex } \\
\text { Test }\end{array}$ & $\begin{array}{c}\text { Bentonite } \\
\text { Test }\end{array}$ \\
\hline $1: 20$ & $1: 128$ & $1: 64$ \\
$1: 10$ & $1: 64$ & $1: 64$ \\
$1: 60$ & $1: 64$ & $1: 128$ \\
$1: 40$ & $1: 64$ & $1: 64$ \\
$1: 10$ & $1: 256$ & $1: 16$ \\
0 & $1: 16$ & $1: 8$ \\
\hline
\end{tabular}

For routine testing three dilutions, $1: 4,1: 8$, and $1: 16$, were found sufficient for both flocculation tests. Positive tests may be titred to the endpoint. In occasional cases zone inhibition occurred at a dilution of $1: 4$ but not at higher dilutions.

Effect of Heat.-Both fresh sera and sera inactivated at $56^{\circ} \mathrm{C}$. for 30 minutes as for the complement-fixation test were found suitable for the bentonite hydatid test. Inactivated serum was less suitable for the latex hydatid test. Inactivation reduced the titre considerably. The temperature of the test is also of importance: $56^{\circ}$ C., as used for the rheumatoid latex test (Singer and Plotz, 1956), rendered the latex hydatid test negative, or positive at a minimal dilution only. Fresh specimens incubated at $37^{\circ} \stackrel{-}{=}$ C. for the test, followed by $4^{\circ} \mathrm{C}$. overnight, gave $\overrightarrow{\vec{\rho}}$ best results. The omission of overnight standing resulted in a loss of sensitivity (Table III).

TABLE III

EFFECT OF HEAT ON LATEX HYDATID TEST

\begin{tabular}{|c|c|c|c|c|}
\hline \multirow{3}{*}{$\begin{array}{c}\text { Test } \\
\text { Temperature } \\
90 \text { Minutes }\end{array}$} & \multirow{3}{*}{$\begin{array}{l}\text { Additional } \\
\text { Incubation }\end{array}$} & \multicolumn{3}{|c|}{ Titres of Sera } \\
\hline & & \multirow{2}{*}{ Fresh } & \multicolumn{2}{|c|}{ Inactivated 30 Minutes } \\
\hline & & & $56^{\circ} \mathrm{C}$ & $60^{\circ} \mathrm{C}$. \\
\hline $\begin{array}{l}\text { Room } \\
37^{\circ} \mathrm{C} \\
56^{\circ} \mathrm{C} . \\
37^{\circ} \mathrm{C}\end{array}$ & $\begin{array}{l}\text { Overnight } 4^{\circ} \mathrm{C} . \\
\text { None" }\end{array}$ & $\begin{array}{l}1: 16 \\
1: 32 \\
0 \\
0\end{array}$ & $\begin{array}{l}1: 8 \\
1: 8 \\
1: 4 \\
0\end{array}$ & $\begin{array}{c}\text { Undiluted } \\
\text { ö } \\
\text { 0 }\end{array}$ \\
\hline
\end{tabular}

Effect of Varying Amounts of Antigen.-The $N$ optimum minimal amount of cyst fluid to be used 음 for one batch of sensitized particles is given $\rightarrow$ above. Smaller amounts produced less satis- و factory results. Table IV shows that in some

TABLE IV

EFFECT OF VARYING AMOUNTS OF ANTIGEN ON LATEX HYDATID TEST IN THREE SPECIMENS

\begin{tabular}{c|l|l|l}
\hline $\begin{array}{c}\text { Latex Coated with } \\
\text { Cyst Fluid (ml.) }\end{array}$ & \multicolumn{3}{|c}{ Titres } \\
\hline 0.5 & $1: 64$ & $1: 256$ & $1: 64$ \\
0.4 & $1: 64$ & $1: 256$ & $1: 64$ \\
0.25 & 0 & $1: 64$ & $1: 8$ \\
0.5 & 0 & $1: 64$ & 0 \\
(diluted 1:2) & & & \\
\hline
\end{tabular}

strongly reacting sera reduction of the amount of antigen still gave sufficient sensitivity, while in another specimen it rendered the latex hydatid test negative.

\section{Discussion}

While bentonite particles have been sensitized $\stackrel{8}{8}$ with helminthic antigens, latex particles have not $₹$ been coated with such antigens in the past. The 을 present study has demonstrated successful $\supset$ sensitization of latex particles with hydatid antigen, and application of both latex and bentonite particles in simple diagnostic procedures ? for human hydatid disease.

This study is essentially a comparison of results $\underset{\omega}{N}$ with complement-fixation and flocculation tests. 0 As the percentage distribution of positive and

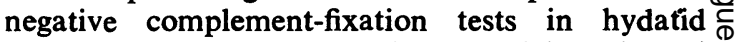
disease and its relation to the Casoni intradermal $\stackrel{\mathcal{D}}{?}$ tests have been the subject of numerous reports 0 (Dew, 1928; Fairley and Kellaway, 1933 ; 웅 Bensted and Atkinson, 1953), no attempt was $\stackrel{\mathbb{\Omega}}{\circ}$ made to ascertain how many of the specimens $\mathbb{\Phi}$ negative with all tests were from patients with $\frac{\circ}{\sigma}$ hydatid disease and with disease other than 
hydatid. In all cases with positive tests diagnosis was ascertained whenever possible. Flocculation tests closely parallel complement-fixation tests. They are simpler, and seem suitable as alternative or screening tests where facilities for complement fixation are not available. While it appears possible that the flocculation tests are slightly more sensitive than the complement-fixation test, no definite statement to that effect seems permissible, until more cases with surgical confirmation and with diverging results are available.

The latex hydatid test has the advantage of a simpler preparation of sensitized particles and reading with the naked eye. The bentonite hydatid test is more rapid, once the stock and sensitized particles have been prepared. No definite superiority of one flocculation test over the other as regards sensitivity has been established.

The grading of $3+$ and $4+$ as positives only as for the bentonite trichinosis test (Bozicevich et al., 1951) corresponded well with results for the bentonite hydatid test. Grade 2 readings were infrequent, and were accompanied by negative latex and complement-fixation tests. Of four sera with grade 2 readings two were from patients operated on more than 10 years previously. There was no evidence of recurrence. In the remaining two cases no evidence of past or present hydatid disease was found.

In the Bozicevich technique serial dilutions were transferred to slides and placed on a rotating apparatus. In this laboratory shaking of serial dilutions in tubes in a Kahn shaker and transferring the contents to slides for reading has been found equally satisfactory. The number of steps involved are the same.

The flocculation tests appear to be specific. The complement-fixation test has been considered specific, but rare false positive results have been reported, with the suggestion that selected cyst fluid suitable in higher dilutions may eliminate false positives (Bensted and Atkinson, 1958). Pooled fluid used in this study was unsuitable in higher dilutions for the tests described. Although no false positives have been encountered, the suitability of selected potent fluids in higher dilutions for the flocculation tests will be the subject of further study.

The effect of temperature on the latex test is of some interest. Inactivation by heating sera at $56^{\circ} \mathrm{C}$. reduced the titre considerably. Preheating to $60^{\circ} \mathrm{C}$. rendered the test negative or positive in the undiluted serum only. A peculiar effect was the complete negativity of the test on fresh sera when the test was carried out at $56^{\circ} \mathrm{C}$., while giving a low positive titre with a test temperature of $56^{\circ} \mathrm{C}$. on previously inactivated sera. Some of these findings are similar to those reported by Bryce et al. (1924) on precipitin tests, showing a gradual decrease in the activity of the precipitating antibody of sera when they were preheated, with total loss at $60^{\circ} \mathrm{C}$. No such effect was observed on the complement-fixing property.

Little work has been done since on the nature of the hydatid antibodies. Recently Magath (1959) obtained a positive complement-fixation test on a $\gamma$ globulin fraction of a serum after electrophoretic separation, with no activity in the other fractions. Precipitin tests in double diffusion agar were performed on whole serum with antigenic fractions, but not with fractions of antiserum. In a preliminary experiment in this laboratory, $\gamma$ globulin fractions were prepared from three positive hydatid and three negative sera, as described in a previous paper (Whillans and Fischman, 1958). The latex test was positive in the fractions of the positive and negative in the control sera, with no activity in any of the supernatants.

As there is evidence of more than one antigen being present in cyst fluid (Senekji, 1941; Magath, 1959), further work is needed to characterize the antibodies involved, and their relation to the hydatid antigens.

The author is indebted to Drs. G. C. T. Burns, J. Foley, D. W. Sabiston, R. C. Taylor, Messrs. J. W. Carroll, G. R. George, and J. G. Smith for some of the positive specimens.

\section{REFERENCES}

Bensted, H. J., and Atkinson, J. D. (1953). Lancet, 1, 265. Bensted, (1958). Brit. med. J., 2, 203.

Bozicevich, J., Tobie, J. E., Thomas, E. H., Hoyem, H. M., and Ward, S. B. (195i). Publ. Hlth Rep. (Wash.), 66,806.

Bryce, L. M., Kellaway, C. H., and Williams, F. E. (1924). Aust. J. exp. Biol. med. Sci., 1, 77.

Dew, H. R. (1928). Hydatid Disease. Australasian Medical Publishing Co., Sydney.

Fairley, K. D. (1923). Med. J. Aust., 2, 27.

Fairley, Kellaway, C. H. (1933). Aust. N.Z. J. Surg., $2,236$.

Garabedian, G. A., Matossian, R. M., and Djanian, A. Y. (1957). J. Immunol., 78, 269.

Magath, T. B. (1959). Amer. J. clin. Path., 31, 1.

Sadun, E. H., Norman, L., Allain, D. S., and King, N. M. (1957). $J$. infect. Dis., 100, 273 .

Senekji, H. A. (1941). Trans. roy. Soc. trop. Med. Hyg., 34. 401.

Singer, J. M., and Plotz, C. M. (1956). Amer. J. Med., 21, 888.

Whillans, D. (1950). J. clin. Path., 3, 56.

and Fischman, A. (1958). Ann. rheum. Dis., 17, 383. 